\title{
DEMAND FOR NATURAL GAS BY HOUSEHOLDS AT THE STATE LEVEL: TWENTY YEARS OF EFFORT
}

\author{
John H. Herbert*
}

\section{Introduction}

The effect of the price of natural gas, the price of any substitute sources of energy, weather, and other factors on residential natural gas demand, is estimated by econometric methods on a recurring basis by public and private organizations. Gas utilities use such estimates in rate proceedings before state public utility commissions. Statistical groups in government and trade associations produce forecasts from them. Regional agencies use them in analyzing the effect of gas price increases on regional economic growth. The importance of reliable estimates of such effects, particularly price effects, is emphasized by the recent financial problems of the Washington Public Power Supply System (WOOPS). One explanation offered for these problems is the inability of economists to convince utility executives that the own-price elasticity for electricity was non-zero.

Several innovations are presented in this paper. An economic model, based on the Balestra and Nerlove (B\&N) formulation, is specified. This new model does not require the use of a surrogate (lagged dependent) variable to represent the relative fixity of the capital equipment stock. A more general and informative statistical model is estimated, and the effect on gas demand of tax credits for energy investments is considered for the first time here. Data issues are also examined in greater detail.

A tax credit elasticity is estimated to be positive and significant at the five percent significance level. A decline in gas demand in 1974, apparently due to the increased energy awareness following the embargo, is estimated. All elasticities reported in this paper are more accurate, as indicated by lower t-ratios, than comparable elasticities reported in previous studies.

The paper begins with a reexamination of the $B \& N$ model. A principal assumption of this model is that gas use per customer is very price inelastic, essentially zero, in the short-run. The B\&N model is used as a basis for a new economic model. A detailed discussion of the vari-

*The author would like to thank Dr. Erik Slud of the Math/Stat Department at the University of Maryland, and Drs. Nancy Kirkendall, Doug Hale, and Phil Kott of the Energy Information Administration and the referees for comments on earlier drafts. The opinions expressed are those of the author and do not necessarily represent those of the Energy Information Administration. ables and observational units used to estimate the coefficients for this new model ensues. The statistical model is delineated next. Preliminary and final results for the estimated model are then presented and discussed. This is followed by a comparison of some of the elasticities in this study with elasticities reported from other studies. All studies indicate that the short-run own-price elasticity, while inelastic, is clearly different from zero.

\section{The Balestra and Nerlove Economic Model}

The Balestra and Nerlove model can be characterized as the joining together of previously identified empirical regularities and logical identities to represent the expected demand behavior of the representative consumer at the state level. Their primary relationships are now enumerated (state subscripts are dropped here and elsewhere as a matter of convenience).

First,

$$
\begin{array}{ll} 
& G_{t}-\left(1-r_{t}\right) G_{t-1}=B_{0}-B_{1 P t}+B_{2}\left[F_{t}-(1-r) F_{t-1}\right] \\
& G_{t}=B_{0}-B_{1} p_{t}+B_{2}\left[F_{t}-(1-r) F_{t-1}\right]+\left(1-r_{t}\right) G_{t-1} \\
\text { or } & G_{t}=B_{0}-B_{1} p_{t}+B_{2}\left[F_{t}-(1-r) F_{t-1}\right]+B_{0} G_{t-1}
\end{array}
$$

where

$\mathbf{G}=$ demand for gas normalized for weather,

$r_{s}=$ depreciation rate for gas appliances,

$\mathrm{p}=$ price of gas deflated by the consumer price index,

$F=$ aggregate demand for all fuels normalized for weather (discussed as either a surrogate for space-heating requirements or for the stock of appliances),

$r=$ constant depreciation rate for non-gas appliances, and

$\mathrm{t}=$ time index.

Second,

$$
F_{t}-(1-r) F_{t-1}=u W_{t}-(1-r) h W_{t-1}
$$

where

W = stock of appliances, and 


$$
\begin{aligned}
& \mathbf{h}=\mathbf{a} \text { constant rate of utilization because of a high } \\
& \text { "and, therefore, constant" efficiency of com- } \\
& \text { bustion. }
\end{aligned}
$$

Third

$$
F_{t}=B_{3}+B_{4} N_{t}+B_{5} Y_{t}
$$

where

$$
\begin{aligned}
& \mathbf{N}=\text { population }, \text { and } \\
& \mathbf{Y}=\text { per capita income. }
\end{aligned}
$$

Equation (4) is viewed as an empirical regularity which has been established by experimentation, that is, by many prior estimations of regression equations by the authors and by others.

The right-hand side of equation (3) is a physical analogue to rationalize the difference $F_{g}-(1-r) F_{t-1}$. This difference is referred to as the new market for residential energy, which is a function of a depreciation rate for all residential energy-using appliances, income, and population growth as specified in equation (4). A similar analogue is used to rationalize the difference $G_{t}-\left(1-r_{t}\right) G_{t-1}$ for gas appliances. This term is referred to as new gas demand. The term $r_{s} G_{t-1}$ represents the size of the replacement market for gas appliances. It is important to note that the $B \& N$ formulation could be stated alternatively either in appliance demand or in fuel demand terms.

Equation (4) is treated as deterministic, and if equation (4) is substituted into equation (2), it yields the general model,

$$
\begin{aligned}
G_{t}= & B_{0}+r B_{2} B_{3}+B_{1} p_{t}+B_{2} B_{4} N_{t}+B_{2} B_{5} Y_{t}+r B_{2} B_{4} N_{t-1} \\
& +r B_{2} B_{5} Y_{t-1}+B_{6} G_{t-1} .
\end{aligned}
$$

The B\&N model assumes that natural gas use per customer is very price inelastic in the short-run. The price elasticity derived from the coefficient in equation (5) is thus thought to reflect the impact of price on the market share of natural gas (a market share elasticity). Equation (3) indicates that, assuming a relatively constant efficiency of combustion, differences in energy demand between time periods can be viewed as a consequence of changes in the number of energy-using appliances between time periods or a simple stock adjustment process. Gas demand is determined by the capability of natural gas to capture its replacement market as determined by the appropriate depreciation rates, and the new market for energy appliances as determined by population growth and income growth.
Weather is controlled for by normalization. Income is viewed as determining the size of the energy-using equipment stock, as represented by the coefficient $B_{3}$, but not as determining relative usage. The coefficient $B_{2}$ represents the proportion of the new residential energy markets captured by natural gas. Since $B_{5}$ represents the proportionate relationship between income level and number of appliances (or fuel demand), the product of $\mathbf{B}_{2}$ and $\mathbf{B}_{5}$ represents the proportionate relationship between income level and the number of gas appliances (or gas demand). Price determines relative market share but not relative usage. Capital equipment efficiency is viewed as constant and independent of price.

The B\&N paper motivated further developments, primarily in estimation technique. Other developments in specification and in actual estimations include Berndt and Watkins (1977), Beierlein et al. (1981), Blattenberger, et al. (1983), Grady (1985), and Herbert (1986).

\section{The Current Economic Model}

Instead of attempting to represent indirectly the average size of the replacement market and the expected size of the new market for residential energy captured by natural gas, an attempt is made here to control directly for annual and between-state differences in the size of the space-heating market, the most significant portion of the residential natural gas market. This is important since it circumvents the need for a lagged dependent variable in the estimated equation. A return to equation (1) and (3) should clarify this point.

Each residential customer is assumed to own only one space-heating appliance (unit). Let

$$
\begin{aligned}
& \text { GS }_{\mathrm{t}-1} \quad=\text { gas space-heating customers in year } \mathrm{t}-1 \text {, } \\
& r_{8} G_{t-1}=\text { gas space-heating customers who must } \\
& \text { year } \mathrm{t} \text {, } \\
& \mathrm{a}\left(\mathrm{r}_{\mathrm{g}} \mathrm{GS}_{\mathrm{t}-\mathrm{L}}\right)=\text { gas space-heating customers who re- } \\
& \text { place an old gas furnace with a new gas } \\
& \text { furnace between year } t-1 \text { and year } t \text {, } \\
& \begin{aligned}
\mathrm{FS}_{\mathrm{t}-1} \quad= & \text { non-gas space-heating customers in } \\
& \text { year } \mathrm{t}-1,
\end{aligned} \\
& \left(1-r_{e}\right) G S_{t-1}=\text { gas space-heating customers from year } \\
& t-1 \text { remaining in year } t \text {, and } \\
& b\left(F S_{1}-(1-r) F S_{t-1}\right)=\text { new market for space-heating } \\
& \text { customers captured by natural gas be- } \\
& \text { tween year } t \text { and year } t-1 \text {. }
\end{aligned}
$$


Thus, the number of gas space-heating customers in year $t$ is defined as

$$
G S_{t}=a\left(r_{z} G S_{t-1}\right)+b\left(F S_{t}-(1-r) F S_{t-1}\right)+\left(1-r_{z}\right) G S_{t-1}
$$

This definition for number of gas space-heating customers (appliances) is an analogue for the B\&N general model, except that the proportions $\mathrm{a}$ and $\mathrm{b}$ are represented explicitly, rather than being a function of the price of natural gas and other factors in some year $t$.

In the B\&N formulation, gas demand (GAS) was normalized by heating degree days (HDD). In the present formulation, HDD and GS are moved to the right-hand side of the equals sign, and both GAS and GS are normalized by the number of customers (CUS):

$$
\text { GAS/CUS }=f_{x}([G S / C U S] \cdot H D D)=f_{x}(H R),
$$

where $f_{x}$ is a function that depends on other factors in addition to HR. The variable HR denotes space-heating requirements and has the following interpretation.

Average gas demand per customer can be expected to vary depending on the fraction of space heating to total gas customers (GS/CUS) and heating degree days (HDD). When two states have the same number of HDD, but the second state has twice the fraction of space-heating customers, heating requirements for the average customer can be expected to be approximately twice as great in the second state, other things being equal. Alternatively, when two states have the same fraction of space-heating customers, but the second state has twice as many heating degree days, space-heating requirements for the average customer can be expected to be approximately twice as great.

There are distinct advantages in using the HR variable rather than just heating degree days (HDD) as is usually done. Space-heating customers consume more natural gas than nonspace-heating customers. In a period of rising natural gas prices and of a rising proportion of gas space-heating customers, for example, there will be a tendency to understate the effect of price if changes in the proportion of space-heating customers are not controlled. The natural gas space-heating requirements variable captures more of the between-state variability in gas sales than would otherwise be the case.

The variable $H R$ is one of the factors considered in the present analysis. Other variables are the average price of natural gas in constant dollars (PG), the average price of electricity in constant dollars (PE), a dummy variable for 1974 (D74), and an indicator of cumulative tax credit investments (TC). The dependent variable is gas demand per customer (GAS/CUS). Therefore, the general economic relationship is,

$$
\text { GAS/CUS = f(PG,HR,PE,D74,TC). }
$$

Each of these variables, their associated coefficients, and other data-related issues will be discussed next.

\section{Variables}

As discussed in greater detail by Grady (1986), the use of sales per customer, ${ }^{\prime}$ and not aggregate sales or sales per capita, has several advantages. Reliable data concerning restrictions by utilities on the addition of new natural gas space-heating customers or on the annual changes in the availability of natural gas to households between years within particular states are not available. Changes in both these factors affect the aggregate size of the residential market independent of price, income, and other factors, but do not affect use per existing customer. This emphasis also focuses attention on the aggregate response of gas customers to differences in price and the other factors.

In forming the $\mathrm{HR}$ variable, heating degree day data ${ }^{2}$ needed to be adjusted, since, as described in particular for this application in Doman, et al. (1986), and in general in Warren and Le Duc (1981), gas demand data are based on billing results and approximately represent demand from mid-December of one year to mid-December of the next year. Therefore, heating degree day data were adjusted to reflect this same time period; that is,

$$
\mathrm{AHDD}_{4}=\mathrm{HDD}_{4}+.5 \mathrm{HDD}_{\mathrm{H}-1, \mathrm{DBC}}-.5 \mathrm{HDD}_{\mathrm{LDBC}}
$$

where

$$
\begin{aligned}
& \mathrm{AHDD}_{\mathrm{L}}=\text { adjusted heating degree days for year } \mathrm{t} \text {, }
\end{aligned}
$$

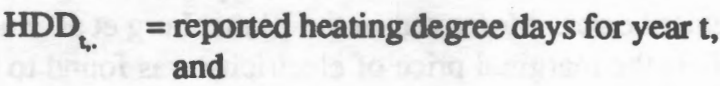

$$
\begin{aligned}
& \begin{aligned}
\mathrm{HDD}_{\mathrm{x} \text { DBC }}= & \text { reported heating degree days for De- } \\
& \text { cember in year } \mathrm{x}(\mathrm{x}=\mathrm{t} \text { or } \mathrm{t}-1) .
\end{aligned}
\end{aligned}
$$

This adjustment is important because of the large fraction of total annual heating degree days that occur in December.

It would be better to adjust sales data rather than heating degree day data. However, monthly data for sales are not available for the time period to make the adjustment for sales.

The coefficient for the price variable (PG) in the present application captures mostly the effect of the price on energy-using behavior rather than energy-choice behavior. In the B\&N model, this effect was assumed to be negligible.

The national consumer price index for all urban 
consumers (CPI-U all items) ${ }^{3}$ is used as the deflator for the PG variable and for all other deflated variables. This deflator is used because the large fraction of natural gas customers live in urban or suburban communities, rather than on farms. A better technique might have been to use state deflators as in Grady (1985). However, limited resources precluded the construction of such a series for all years considered.

No variable is included to account for changes in the proportion of gas customers that use natural gas, either for water heating or for cooking, since such data are not available. Fortunately, evidence from the Census of Housing and the American Gas Association suggests that these proportions did not change much between 1970 and $1980^{4}$ and that natural gas and electricity were competing for these appliance market shares in the chosen states. The inclusion of an average price of electricity variable in constant dollars (PE) is expected to capture variations in gas demand due to differences or changes in equipment stock.

Average, rather than marginal, prices for electricity and for natural gas ${ }^{6}$ are used in the present study for several reasons. For the individual consumer, the marginal cost is the appropriate price to use, if the marginal cost is the known cost to the consumer; however, the bill that the residential customer pays each month is stated in average cost terms, and the total cost per year is also stated in average cost terms. A marginal cost series would have to be calculated from actual billing schedules for each utility in a state and then weighted and summed to the state level. This would be a worthwhile enterprise in and of itself and useful for such purposes as examining the covariation in the average and the marginal price series, but it is labor-intensive and necessarily introduces measurement error. Moreover, in the Blattenburg et al. study (1983) the marginal price of electricity was found to be insignificant, and the marginal price of natural gas barely significant at five percent significance levels.

There are important advantages to be gained from examining historical administrative records data, rather than more detailed and more recent sample survey data. The former affords us the opportunity to estimate the degree to which policy initiatives or external factors have affected demand behavior. For example, results in the Blattenberg et al. study (1983) indicate that the oil embargo of 1973/1974 had a significant effect on household demand for services from natural gas appliances. Such an effect is similarly considered in the present study by means of a dummy variable (D74).

Another factor considered in this study is the additional effect on gas use of energy conservation and renewable energy investment expenditures, associated with the residential tax credits. These were enacted as part of the
Energy Tax Act of 1978. A series of values for this variable, TC, is obtained by taking the cumulative sum of annual values per capita of "Total current-year residential energy credit (before limitations)" from Internal Revenue Service Individual Tax Returns (various years)' in constant dollars.

Values for TC include expenditures for conservation efforts such as insulation, storm windows and doors, as well as renewable energy expenditures such as solar panels. Years for which disaggregate data were available indicate that conservation expenditures generally represent more than 80 percent of total expenditures. The cumulative sum was used because the majority of such expenditures generally can be expected to stay in place and retain efficiency for the five years considered. This is probably most true for insulation, the largest such expenditure. This examination is particularly relevant because a very large proportion of the households in the analyzed states use natural gas. Therefore, the per capita figures are likely to be representative numbers for gas households.

\section{Observational Units}

A larger number of years (1960-1982) is considered in this study than in previous efforts. These years include a period, the 1960 s, of declining prices in constant dollars and a period, the 1970 s, of rising prices. The Blattenberger et al. study examined the next largest number of years, 14, from 1961 to 1974.

Only a selected set of states is considered: Illinois, Indiana, Ohio, Michigan, Kentucky, West Virginia, and Missouri. These are contiguous states in the east central part of the United States in which average heating degree days calculated over 52 years are similar. The same can be said of crude indicators of changes in the average age of the natural gas equipment stock and of the average age of the housing stock. Large differences in these averages among states may bias the estimated coefficients.

In a related analysis of monthly data by Herbert (1983), residential demand per heating degree day per residential unit was found to be noticeably less in states such as Wisconsin and Minnesota where annual average heating degree days, at 7,603 and 8,732, were greater. Historically, a larger proportion of space-heated households in these states might be expected to have conservation features in place because of the larger savings from such investments.

The thermal integrity of new households built and the efficiency of new furnaces purchased may have begun to improve after 1973, when natural gas and other energy prices began to increase consistently. Therefore, states in which a large proportion of the natural gas customers had new furnaces, or lived in new homes, might be expected 
to use gas differently. In a previous analysis of annual data by Doman et al. (1986), states with a disproportionately large number of new houses were found to use less natural gas, other things being equal.

It is also impossible or difficult to include these factors as part of a regression analysis. Reliable annual values are not available on changes in the housing and natural gas equipment stock. The effect of a long-term average heating degree day variable would be hard to separate from that of an annual heating degree day variable because of their collinearity.

Relevant data were examined to ensure that chosen states did not vary greatly in terms of these factors. The idea was not to have a formal strategy for selecting groups of states, but to make sure that a group of states informally chosen because of their contiguity did not vary greatly in terms of these factors. The relevant statistics are reported in Table 1.

Table 1

Values for Important State Factors

\begin{tabular}{lccc}
\hline State & $\begin{array}{l}\text { Percent of Structures } \\
\text { Built Between } \\
1970-1980^{1}\end{array}$ & $\begin{array}{l}\text { Change in the Percent of Space } \\
\text { Heating to Total Customer } \\
\text { Between 1973-1982 }\end{array}$ & $\begin{array}{l}\text { 52-Year Average } \\
\text { Annual Heating } \\
\text { Degree Days }\end{array}$ \\
\hline Illinois & 19.4 & $81.6-88.0$ & 6091 \\
Ohio & 20.0 & $97.5-98.9$ & 5805 \\
Indiana & 22.0 & $87.3-96.0$ & 5729 \\
Michigan & 22.1 & $92.3-96.3$ & 6798 \\
Missouri & 23.9 & $96.2-97.1$ & 5018 \\
West Virginia & 24.9 & $98.8-98.0$ & 5128 \\
Kentucky & 28.7 & $93.2-98.8$ & 4416 \\
\hline \hline
\end{tabular}

'United States Department of Commerce, Bureau of the Census, Statistical Abstract of the United States 1984, Table No. 1341, p. 750

${ }^{2}$ American Gas Association, various years, Gas Househeating Survey.

'United States Department of Commerce, National Oceanic and Atmospheric Administration, 1983, State, Regional, and National Monthly and Seasonal Heating Degree Days Weighted by Population, Historical Climatology Series 5-1.

\section{The Statistical Model}

A particular structure for the error term is specified in the present application based on previous analyses of monthly data for the North Central Census Region by Herbert (1983) and other information on this market from surveys. Individual state variances are specified, because the variation in average gas use among states can be expected to be dependent upon the combined effect of difficult-to-measure differences in demographics and housing characteristics. Contemporaneous covariances between states are specified, because random, yet similar, annual changes in insolation, wind speed, and general economic activity in contiguous states are likely to affect similarly the variation in gas use. If diverse states such as Florida and Idaho were included in our sample of states, the contemporaneous covariances would be expected to be negative.

The equation to be estimated is:

$$
\begin{aligned}
\ln (\text { GAS/CUS })_{i \mathrm{it}}= & \mathrm{a}+\mathrm{bln}(\mathrm{PG})_{\mathrm{i \textrm {i }}}+\mathrm{cln}(\mathrm{HR})_{\mathrm{i \textrm {i }}}+\mathrm{dln}(\mathrm{PE})_{\mathrm{k}} \\
& +\mathrm{f}(\mathrm{D} 74)_{\mathrm{i}}+\mathrm{g} \ln (\mathrm{TC})_{\mathrm{ik}}+\mathrm{u}_{\mathrm{ik}}
\end{aligned}
$$

where

all variables have been defined previously

$$
\begin{aligned}
& \text { i } \quad=1, \ldots, 7 \text { states, } \\
& \mathrm{t} \quad=1, \ldots, 23 \text { years, } \\
& \text { In = natural logarithm, } \\
& u_{k} \quad=p_{i} u_{i-1}+e_{i k^{\prime}} \\
& E\left(e_{i j}\right)=0 \text {, } \\
& E\left(e^{2}\right)=s_{k j} \text {, } \\
& E\left(e_{i} e_{j j}\right)=s_{i j} \quad(i \neq j) \text {, } \\
& E\left(e_{\mathrm{k}} e_{\mathrm{j}^{\prime}}\right)=0 \quad\left(t \neq t^{\prime}\right), \\
& E\left(u_{k-1} e_{j k}\right)=0 \text {, }
\end{aligned}
$$




$$
\begin{aligned}
& E\left(u_{i o} u_{j}\right)=s_{i j} /\left(1-p_{i j} p_{j}\right) \quad(i=j, i \neq j) \text {, and } \\
& E\left(u_{i o}\right)=0 .
\end{aligned}
$$

A first-order autocorrelation error structure is considered for several reasons. One reason for this structure is general persistence in measured behavior between years which may or may not be considered a consequence of random factors. For example, it could be due to the lack of explicit adjustment for differences among states and changes over time in nonspace-heating equipment stocks in the different states. Another reason is that collectors of the historical data are known to have imputed, or adjusted, values for natural gas utilities based on values for the previous year when complete data were not available.

\section{Estimation Procedure and Estimated Results}

The equation is estimated by a procedure delineated by Parks (1967). In the first step, ordinary least squares are applied to equation (7) and the residuals $\left(\mathrm{u}^{*}\right)$ from this estimation are used to calculate estimates for $p$, that is,

$$
\mathrm{p}_{1}=\sum_{\mathrm{t}=2}^{23} \mathrm{u}^{*} \mathrm{u}^{*} \mathrm{u}_{\mathrm{it}+1} / \sum_{\mathrm{t}=2}^{23} \mathrm{u}^{*}{ }_{\mathrm{it} \mathrm{t}^{2}}^{2}
$$

Estimated values are reported in Table 2.

Table 2

Estimated Values for the Autocorrelation Coefficient

\begin{tabular}{lcr}
\hline State & Coefficient & Standard Error \\
\hline Illinois & .93 & .21 \\
Ohio & .83 & .21 \\
West Virginia & .83 & .21 \\
Missouri & .61 & .21 \\
Kentucky & .70 & .21 \\
Michigan & .67 & .21 \\
Indiana & .45 & .21 \\
\hline
\end{tabular}

As expected, the autocorrelations are found to be positive and different from zero. The average for the seven states is .71. If the inverse of the square root of the number of observations (i.e., .21) is used as an indicator of the standard error of the autocorrelation coefficient, then all coefficients are more than two standard errors from zero. Thus, a test of the hypothesis of zero autocorrelation coefficients for all $\mathrm{i}$ would be rejected.

The estimated autoregressive structure is next factored out, and a transformed series obtained, by the usual procedure of subtracting the product of $p_{i}$ and the lagged value of dependent and independent variables from the corresponding unlagged values. Ordinary least squares is applied to this transformed data series in a second stage, and the residuals ( $u^{* *}$ ) calculated from this estimation are used to obtain estimates for $s_{i j}$. Values for $s$ are calculated with the following formula:

$$
\left.s_{i j}=(1 /[23-q]) \sum_{i=1}^{23} u^{* *}{ }_{i t} u^{* *}{ }_{j i t}\right)
$$

where $q=$ number of parameters

Correlations calculated with the $s_{i j}$ 's are reported below in Table 3. These coefficients are useful indicators of the possible effect of unmeasured random factors on average

\begin{tabular}{|c|c|c|c|c|c|c|c|}
\hline & Missouri & Illinois & Kentucky & Ohio & Indiana & West Virginia & Michigan \\
\hline Missouri & 1.00 & .51 & .32 & .08 & .73 & .39 & .001 \\
\hline Illinois & & 1.00 & .39 & .33 & .59 & .32 & .15 \\
\hline Kentucky & & & 1.00 & .77 & .17 & .54 & .59 \\
\hline Ohio & & & & 1.00 & .02 & .38 & .58 \\
\hline Indiana & & & & & 1.00 & .28 & .01 \\
\hline West Virginia & & & & & & 1.00 & .13 \\
\hline Michigan & & & & & & & 1.00 \\
\hline Variances & .00168 & .00104 & .00073 & .00067 & .00061 & .00055 & .00039 \\
\hline
\end{tabular}
gas demand between states over time.

Table 3

Variances and Estimated Correlations Calculated from the $s_{1 j}$ 's 
Positive values for the correlation coefficients in Table 4 indicate that the effects of random temporal factors, such as insolation values and general economic activity between states for the same time period, tend to be in the same direction. If the states were widely different in terms of these random factors, negative values would be expected. Some of the coefficients are relatively large. This is to be expected if, in fact, the effect of these random factors are similar for the chosen states. Many of the large values are in states, such as Missouri and Illinois, Illinois and Indiana, and Kentucky and Ohio, which share major portions of their borderlines

The relatively low correlation for Indiana and Michigan, when compared with Ohio and Michigan, has the following explanation. A relatively large proportion of the total gas customers in Ohio and Michigan reside either near the borderline between the states or near opposite banks of Lake Erie. For example, during the 1970 s approximately 36 percent of the gas customers in Ohio resided in the Cleveland area, and 42 percent of the gas customers in Michigan resided in the Detroit area. There are a relatively small number of gas customers near the borderline between Michigan and Indiana. An interesting result is the relatively high correlation for Indiana and Missouri, a result which does not have a ready explanation and may be worth future investigation.

A generalized least squares equation is estimated in a third stage estimation using a covariance matrix constructed from the estimated values for $p_{i}$ and $s_{\mathrm{h}}$. The results of the first through third stage estimations are reported below in Table 4.

Table 4

Regression Results

\begin{tabular}{|c|c|c|c|c|c|}
\hline & & \multicolumn{3}{|c|}{ Coefficients } & \multirow{2}{*}{$\frac{\text { Assmptotict-ratio }}{3 \mathrm{~d}}$} \\
\hline \multicolumn{2}{|c|}{ STAGE REGRESSION } & lst & 2nd & $3 r d$ & \\
\hline \multicolumn{6}{|l|}{$\mathbf{V}$} \\
\hline $\mathbf{A}$ & INT & -1.35 & -.36 & -.59 & -3.0 \\
\hline $\mathbf{R}$ & PG & -.36 & -.30 & -.30 & -10.5 \\
\hline I & HR & +.69 & +.59 & +.61 & +31.5 \\
\hline $\mathbf{A}$ & PE & +.14 & +.10 & +.08 & +3.6 \\
\hline B & D74 & -.05 & -.04 & -.03 & -3.3 \\
\hline $\begin{array}{l}\mathbf{L} \\
\mathbf{E}\end{array}$ & TCR & -.003 & -.004 & -.004 & -3.3 \\
\hline
\end{tabular}

The regression results are, in general, quite good. All variable coefficients have the correct sign and are significantly different from zero at the five percent level. The important gas price (PG) and heating requirements (HR) coefficients are especially significant. The price of electricity coefficient is the least stable of all coefficients, which indicates its possible unreliability.

The coefficient of determination $\left(R^{2}\right)$ for the first stage regression is equal to .87 . The most striking result is the stability of the coefficients, especially in the last two regressions.

An estimation including data from only 1970-1982, a period characterized by rising natural gas prices, yielded coefficients similar in magnitude to those reported in
Table 4. This underlines the robustness of the estimated results to the data.

An additional behavioral equation was estimated, which equation included a personal income series in constant dollars (Y) from the Bureau of Economic Analysis." This variable had not been examined initially because previous efforts had found income to be insignificant.

The results of this estimation, using the same method of estimation, indicate that although the income coefficient was positive, it was not especially significant. The results of this final estimation are reported in Table 5. The relative stability of the coefficients is again worth noting.

Table 5

Summary Statistics for the Equation with an Income Variable

\begin{tabular}{|c|c|c|c|c|c|c|c|}
\hline Variable & INT & PG & HR & PE & D74 & TC & $\mathbf{Y}$ \\
\hline Coefficient & -.46 & -.30 & +.59 & +.10 & -.031 & -.004 & +.058 \\
\hline Standard error & .19 & .03 & .02 & .02 & .010 & .001 & .031 \\
\hline t-statistic & -2.34 & -10.83 & +23.96 & +4.21 & -3.06 & -3.42 & +1.89 \\
\hline
\end{tabular}




\section{Comparison of Estimated Results From Several Studies}

Previous examinations of residential natural gas demand consider a diversity of time periods, states, and models. Even though previous efforts include a lagged dependent variable as an independent variable, it is possible to compare the magnitude of estimated elasticities and t-ratios from several of the studies, since a similar dependent variable and a similar log linear functional form is used. These figures are reported in Table 6.

Table 6

A Comparison of Elasticities and t-ratios from Several Studies (t-ratios are presented in brackets)

\begin{tabular}{|c|c|c|c|c|c|c|c|c|}
\hline \multirow[t]{3}{*}{ Variable } & \multicolumn{8}{|c|}{ Study } \\
\hline & \multicolumn{2}{|c|}{ This Study } & \multicolumn{2}{|c|}{ Blattenberger } & \multicolumn{2}{|c|}{ Beierlein ${ }^{4}$} & \multicolumn{2}{|c|}{ Herbert } \\
\hline & Est. & t-ratio & Est. & t-ratio & Est. & t-ratio & Est. & t-ratio \\
\hline PG & -.30 & [10.5] & $-.32^{1}$ & [2.5] & -.35 & [7.1] & -.22 & [5.2] \\
\hline PE & +.08 & [3.6] & $+.02^{2}$ & [1.9] & +.17 & [2.1] & +.10 & [2.5] \\
\hline HR & +.61 & [31.5] & $+.52^{3}$ & [17.6] & $N_{A}{ }^{3}$ & NA & +.25 & [5.4] \\
\hline
\end{tabular}

${ }^{1}$ marginal price of natural gas was used

'marginal price of electricity was used

Theating degree days were used

'results for their seemingly unrelated estimation are reported

'insignificant results were estimated but estimated magnitudes were not reported using the ratio of current year's heating degree days to the prior year's heating degree days as an independent variable.

The own price elasticity is clearly inelastic, similar in magnitude, but different from zero in all studies. Since the Blattenberger and Herbert studies use sales per customer as the dependent variable, these results are at odds with the $B \& N$ assumption that the short-run elasticity is equal to zero. There is also some evidence of substitution effects. The B\&N model did not consider substitution effects. Finally, heating degree days are important in all studies that reported such results and, not too surprisingly, more important in regions that include significant numbers of space-heating customers. The Northeast Census Region, which was examined in the Beierlein et al. and the Herbert studies, contains the smallest fraction of space heating to total gas customers of any region in the United States.

The t-ratios for the gas price coefficient were greater in this study than in other studies. This study and the Blattenberger et al. study found a significant oil embargo effect of the same magnitude (i.e., -.03). The effect of tax credits on gas demand was considered for the first time here. The magnitude of the estimated elasticity, while small, was statistically significant. Previous efforts have either assumed or found short-term income effects to be statistically insignificant. This was also the case here. Finally, an electrical energy cross-price elasticity for natural gas was found to be significant but unstable.

\section{Summary and Conclusions}

It has been 20 years since the seminal work by Balestra and Nerlove was published. In the construction of their behavioral model, they assumed that the demand for services by households from gas appliances was perfectly inelastic with respect to price and income. This study, and other studies since then, have cast much doubt on this assumption.

Balestra and Nerlove attempted to estimate residential natural gas demand behavior for a period when this market was rapidly growing in many states--a much more difficult market in which to estimate demand relationships than the relatively mature market considered in the present study. Perhaps a partial explanation for their contradictory results (they found implicit depreciation rates less than zero) was their failure to account for the large growth in the number of space-heating customers in the late 1950s and early 1960 s.

The logical framework of the $B \& N$ study has provided a most fruitful starting point for this and many other studies, and the candor of their discussion provides much food for thought. Reexamination of their study resulted in the specification of an independent variable which precluded the inclusion of a lagged dependent variable as an independent variable. Such independent variables tend to 
dominate regression equations at the expense of the other variables considered. It appears that this new model enables the variability in gas demand to be better explained by the primary economic variables. All t-ratios were greater than three and variable coefficients were relatively stable among all estimated equations. Both the oil embargo of 1973/1974 and the tax credits of 1978 were seen to have a statistically significant effect on gas demand.

Despite, and as a consequence of, the generally good results, work remains to be done. First, a systematic evaluation of the statistical assumptions would be useful and may lead to an even better specified model. Second, a specific attempt to decisively separate the independent effects of tax credit investments on gas demand, the price of natural gas, and the price of electricity, is probably warranted.

\section{NOTES}

${ }^{1}$ American Gas Association (various years), Gas Facts (Arlington, VA).

${ }^{2}$ United States Department of Commerce, National Oceanic and Atmospheric Administration, State, Regional, and National Monthly and Seasonal Heating Degree Days Weighted by Population (Ashville, North Carolina, 1983).

'United States Department of Labor, Bureau of Labor Statistics, LABSTAT, (Washington, D.C., 1984).

'This was estimated by calculating the number of households whose primary water-heating and cooking fuels were natural gas in 1970 and in 1980 from the Census of Housing as a proportion of the number of residential customers in 1970 and 1980, respectively, from the American Gas Association Gas Facts. The proportions were generally similar in 1970 and in 1980 for all states.

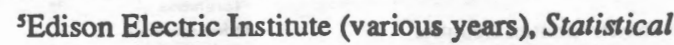
Yearbook of the Electric Utility Industry (Washington, D.C.).

-American Gas Association (various years), Gas Facts (Arlington, VA).

'United States Department of Treasury, Internal Revenue Service (various years), Statistics of Income, Individual Income Tax Returns (Washington, D.C.).

This information was received from compilers of the data at the American Gas Associations.

'United States Department of Commerce, Bureau of Economic Analysis (various years), Survey of Current Business (Washington, D.C.).

\section{REFERENCES}

American Gas Association (various years). Gas Facts. Arlington, VA.
American Gas Association (various years). Gas Househeating Survey. Arlington, VA.

American Gas Association. Historical Statistics of the Gas Utility Industry 1966-1975. Arlington, VA, 1977.

Balestra, Pietro. The Demand for Natural Gas in the United States. Amsterdam: North Holland Publishing Company, 1967. , and Marc Nerlove. "Pooling Cross Section and Time Series Data in the Estimation of a Dynamic Model: The Demand for Natural Gas." Econometrica. 34 (1966). 585-613.

Beierlein, James G., James W. Dunn and James C. McConnon, Jr. "The Demand for Electricity and Natural Gas in the Northeastern United States." The Review of Economics and Statistics. 63 (1981). 403-408.

Berndt, E. R. and G. C. Watkins. "Demand for Natural Gas: Residential and Commercial Markets in Ontario and British Columbia." Canadian Journal of Economics. X (1977). 97-111.

Blattenberger, Gail R., Lester D. Taylor, and Robert K. Rennhack. "Natural Gas Availability and the Residential Demand for Energy." The Energy Journal. 4 (1983). 23-45.

Doman, Linda E., John H. Herbert, and Renee Miller. An Assessment of the Quality of Selected EIA Data Series, Energy Consumption Data. Washington, D.C., 1986.

Fels, Margaret F. and Thomas H. Woteki. "Indices of Energy Consumption: An Exploratory Analysis of a Utility's Monthly Billing Data." Energy. (1979). 1117-1130.

Grady, S. T. "Regional Demand for Natural Gas in the Residential Sector." Review of Regional Studies. 15:2 (1985). 19-28.

Herbert, J. H. "Recent Residential Sales of Natural Gas to Residential Customers in the North Central United States." Natural Gas Monthly. 3 (1983). XVIIXXXVII.

- "Data Analysis of Sales of Natural Gas to Households in the United States." Journal of Applied Statistics. 13: 2 (1986). 199-211.

- "Data Matters-Specification and Estimation of Natural Gas Demand per Customer in the Northeastem United States." Computational Statistics and Data Analysis. (1987). 67-78.

Parks, R. W. "Efficient Estimation of a System of Regression Equations When Disturbances are Both Serially and Contemporaneously Correlated." Journal of the American Statistical Association. (1967). 500-509.

United States Department of Commerce, Bureau of the Census (1960-1980). Census of Housing. Washington, D.C.

Warren, Henry E., and Sharon K. Le Duc. "Impact of Climate on Energy Sector in Economic Analysis." Journal of Applied Meteorology. (1981). 1431-1439. 